\title{
Development of IoT Based Fresh Food Delivery Tracking System Using GPS
}

\author{
Man-Ching YUEN ${ }^{\mathrm{a}, 1}$, Yip-Hin CHOI ${ }^{\mathrm{b}}$, Tsun-Hin $\mathrm{NG}^{\mathrm{c}}$, Chun-Tung POON ${ }^{\mathrm{c}}$ and \\ Kin-Chung FUNG ${ }^{\text {d }}$ \\ ${ }^{a}$ Centre for Applied Data Science, Department of Journalism and Communication, \\ Hong Kong Shue Yan University, Hong Kong, China \\ ${ }^{\mathrm{b}}$ School of Science and Technology, The Open University of Hong Kong, \\ Hong Kong, China \\ ${ }^{\mathrm{c}}$ Department of Computer Science, Hong Kong Baptist University, Hong Kong, China \\ ${ }^{\mathrm{d}}$ Department of Information Technology, Hong Kong Institute of Vocational Education \\ (Tsing Yi), Hong Kong, China
}

\begin{abstract}
Home delivery service is an essential service for online shopping. The need for reliable delivery system to ensure freshness of foods is challenging with consumers' busy schedule and heavy traffic. An efficient fresh food delivery tracking system is designed and implemented for tracking the fresh food delivery ordered on an online shopping system. The proposed system made use of Internet of Things (IoT) technology, Global Positioning System (GPS) and a smart online shopping system. Using this GPS system, consumers are able to track their delivery and arrival of their grocery to ensure the freshness of products. To create the user-friendly access website, we have included four functions in this website: Online shopping cart, system to support various payment methods, GPS food tracking system, and members' easily access account data system. Since the cost of this fresh food delivery tracking system is low, it is suitable for online shop of start-ups.
\end{abstract}

Keywords. Internet of things; IoT; Global Positioning System; GPS; delivery tracking

\section{Introduction}

Continuous progress in technologies has led the development of new tools and programs for improving the quality of consumers' needs and satisfaction. Many enterprises keep their data at a cloud database that runs on a cloud computing platform and can be accessed at anytime at anywhere. Since the cloud technology offers pay-asyou-go payment policy, the cloud storage can be expanded as needed and enterprises can reduce costs on infrastructure. However, the security issue of data stored in the cloud is a big concern, especially for customers' personal information such as payment details. Therefore, many new payment methods, such as digital wallets, are launched, and customers have a lot of choices on e-payment methods. With rapid evolving

1 Corresponding Author, Man-Ching YUEN, Centre for Applied Data Science, Department of Journalism and Communication. Hong Kong Shue Yan University, Hong Kong, China; E-mail: mcyuen@hksyu.edu. 
technologies, newer technologies (e.g., Internet of Things, robots) and business models (e.g., member's subscription) emerged to embrace customers' consumption decisions [1]. The Internet of Things (IoT) describes the network of physical objects, which are embedded with sensors, software, and other technologies. By using different types of sensors, IoT devices can collect different real-time data, such as locations of sensors, temperatures, humidity, and occurrences of triggered events. With big data and predictive analytics, retailers can now offer better appealing offers, better target their customers, and develop better tools to encourage consumers to make purchase decisions. Meanwhile, consumers are receiving more beneficial offers to enable them to make more informed decisions [2].

Many factors that affect consumers' purchase decision. One concept, known as the "holistic customer experience" indicated that customer's cognitive, affective, emotional, social, and physical responses to the retailer is the success of a retailer among its competitors [3]. With technologies, retailers are progressing to meet the evolving consumer behaviors. These include using Internet of Things, virtual or augmented reality, robots, and artificial intelligence to help consumers to make good decisions and increase their satisfaction to purchase [4-5].

Online shopping has been shown to provide more satisfaction to consumers who seek for convenience and speed [6]. It is convenience because it opens 24 hours per day, and 7 days per week. Consumers are able to access the online shop at their convenient time as long as they can access the Internet. Although the customers rarely have a chance to touch and feel the product, they are able to get product information from website and products' reviews by other customers before making their purchase decision. This gives customers more chances to compare price from different websites and to find the product with a lower price than buying from local retailing stores. It also save time as customers do not have to stuck in the traffic, look for a parking spot, or wait in checkout lines [7]. Meanwhile, there are some factors that impede consumers from online shopping, such as unsecured payment, slow shipping, intangibility of online product, competition with branded products, and lack of social contact [8-11]. Hence, retailer should continue to improve or create effective online shopping tools that could ease the customers concerns to persuade customer to use their online shopping system [12].

The basic purpose of a low-cost fresh food delivery tracking system is to track a specific target fresh food ordered on an online shopping system. The vehicle for fresh food delivery has a tracking device which uses Global Positioning System (GPS) module to get its current location and inform the customers by updating the information in the database of the online shopping system. The tracking device is a type of IoT device. The Global Positioning System (GPS) is a satellite-based navigation system made up of at least 24 satellites, which is owned by the United States government. The satellites constantly send out signals, while the receiver in a GPS module listens for these signals. Once the receiver in a GPS module calculates its distance from four or more GPS satellites, it can figure out the location of the GPS module. In this way, GPS can effectively get the real-time location information from satellites in the form of latitude, and it is commonly used in many vehicle tracking systems. By using GPS, our online shopping system can give confident to customers on the fresh food delivery process. As the cost of this fresh food delivery tracking system is low, it is suitable for online shop of start-ups. The proposed vehicle tracking system connecting with an online system is not only suitable for fresh food delivery, but it has many applications, such as agricultural farming monitoring system to monitor automatic tasks done by 
robots. Since the cost of hardware is low, it is very suitable for start-ups to develop their own system. The fresh food delivery tracking system proposed in the paper has the following objectives:

- To obtain geographic location of vehicle carrying target fresh food in real-time using the GPS module

- To transmit the geographic location of vehicle carrying target fresh food to the web server after a specified time interval using the mobile network signal

- To design a database to store and manage received vehicles' location information

- To allow customers to view the location of vehicle on Google map when he sends out a request on the online shopping system

- To allow customers to get the estimated delivery time of ordered fresh food

\section{Related Works}

\subsection{Vehicle Tracking Systems}

Vehicle tracking systems attracted much attention in the past years [13], such as antitheft tracking system [14-15], vehicle detection and tracking system [16], bus tracking system [17] and web-based vehicle tracking system [18].

\subsubsection{Anti-theft tracking system}

Maurya et al. [14] proposed an anti-theft vehicle tracking system. It is used for tracking and positioning of any vehicle by using GPS and GSM technology. The system continuously monitors a moving vehicle and reports the status of the vehicle on demand. The system can automatically send a reply to the requesters on indicating the position of the vehicle in terms of latitude and longitude in real time. Liu et al. [15] proposed a vehicle anti-theft tracking system which is controlled by an RFID model to switch on and off. When the car is stolen, the sensors mounted inside the vehicles are triggered, and the system will send the location information collected by the GPS module to the owner's mobile phone. The owner can track the position of the stolen car.

\subsubsection{Vehicle detection and tracking system}

Li [16] proposed a moving vehicle detection and tracking system, which consists of road detection, vehicle detection and vehicle tracking. The road detection algorithm can detect either well-structured or unstructured roads, so the system works well at outdoor environment in real-time mode.

\subsubsection{Bus tracking system}

Eken and Sayar [17] proposed a smart bus tracking system that allows passengers to use scan QR placed at bus stop to view estimated bus arrival times and buses' current locations and bus routes on a map. 


\subsubsection{Web-based vehicle tracking system}

Salim and Idrees [18] proposed a web-based vehicle tracking system enables enterprises owners to check and track the present and past position recorded of the target vehicles on Google Map in a specified website. It is a challenge and opportunity to develop a website of specified application which can make good use of vehicle tracking system by using GPS technology.

\subsection{Fresh Food Delivery Systems}

There exist a number of previous works on fresh food delivery systems [19-22]. Hsu et al. [19] proposed a solution for the vehicle routing problem which is to minimize not only the fixed costs for dispatching vehicles, but also the transportation costs for violating time-windows. They suggested that the solution is suitable for the perishable food delivery. Nakandala et al. [20] developed an intelligence total cost model that includes various costs incurred during transportation from farms to retailers by using genetic algorithms and fuzzy genetic algorithms. Wang and Yin [21] proposed a model for optimal route selection, temperature control and the average speed of vehicle for fresh food delivery. Chen et al. [22] proposed a model for optimal route selection for minimizing emission of carbon dioxide. However, all existing work are evaluated by simulation experiments or mathematical model, and do not consider the way on how to inform the customers' updated information as soon as possible. One of the main contributions of our work is to develop a prototype of online shopping system which allows consumers to get the latest information of fresh food delivery by using IoT devices and GPS technology.

\section{Methodology Implemented}

\subsection{Project Scope}

The HKMall online shopping system is designed for 4 main users: Administrator, Staff, Member and Visitor. The administrators have the full access to the system. The staff can manage the foods information and assist customers to handle their requests or questions. The visitors/members can browse the website and make their purchase decision. Figure 1 shows the system overview.

Our online shopping system has 4 parts:

- Online shopping cart - Members add their favorite items to the shopping cart system for purchase.

- Support new generation of payment methods - When members making purchases on our online shopping system in Safari on their iPhone, iPad, or Mac, they can use Apple Pay without having to create an account or fill out lengthy forms. Additionally, with Touch ID on MacBook Pro, making payment transaction is quicker, easier, and more secure with this system.

- $\quad$ Track Arrival for ordered goods by GPS - When the order was paid, members can go to the 'Personal' page to review the purchase progress. We also provide GPS tracking system to track the real-time location of the ordered goods to make sure the goods can be delivered within a reasonable time to ensure the freshness of 
goods. By using Google Map API, the GPS tracking system also show a suggested route offered by Google Map API.

- $\quad$ Ease of accessing user data - Members can access their data easily. These data include their purchase histories and account information

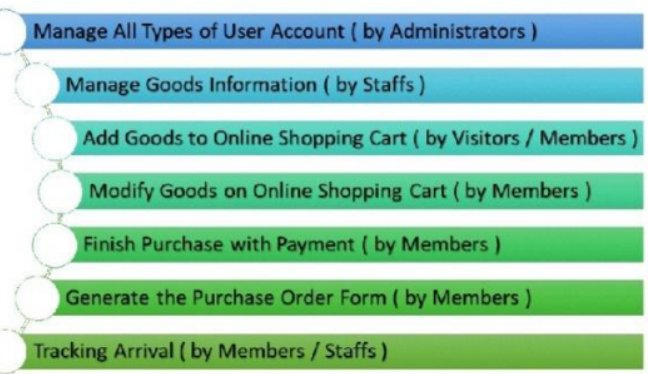

Figure 1. System overview

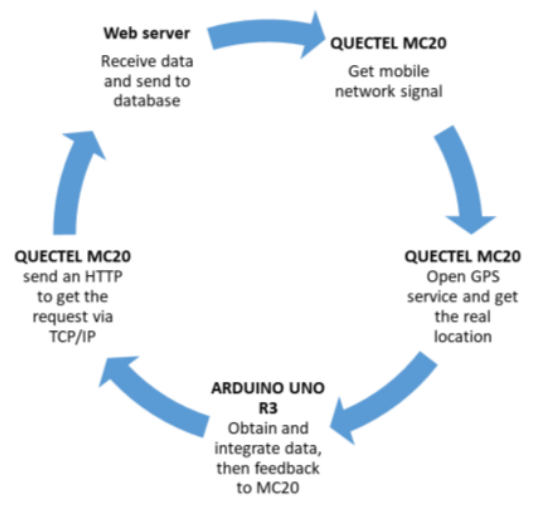

Figure 2. GPS tracking system

\subsection{GPS Tracking System}

Figure 2 shows the GPS structure of the HKMall system. QUECTEL MC20 is the core of our GPS system. It provides GPS service to obtain real-time location via mobile network signal. When the location data (i.e., latitude and longitude) was obtained and integrated, data will feedback to the QUECTEL MC20. Then, QUECTEL MC20 will send HTTP to get the request via TCP/IP. Finally, the data will be sent to Web server and uploaded to our database. An illustrative example is shown in Figure 3.

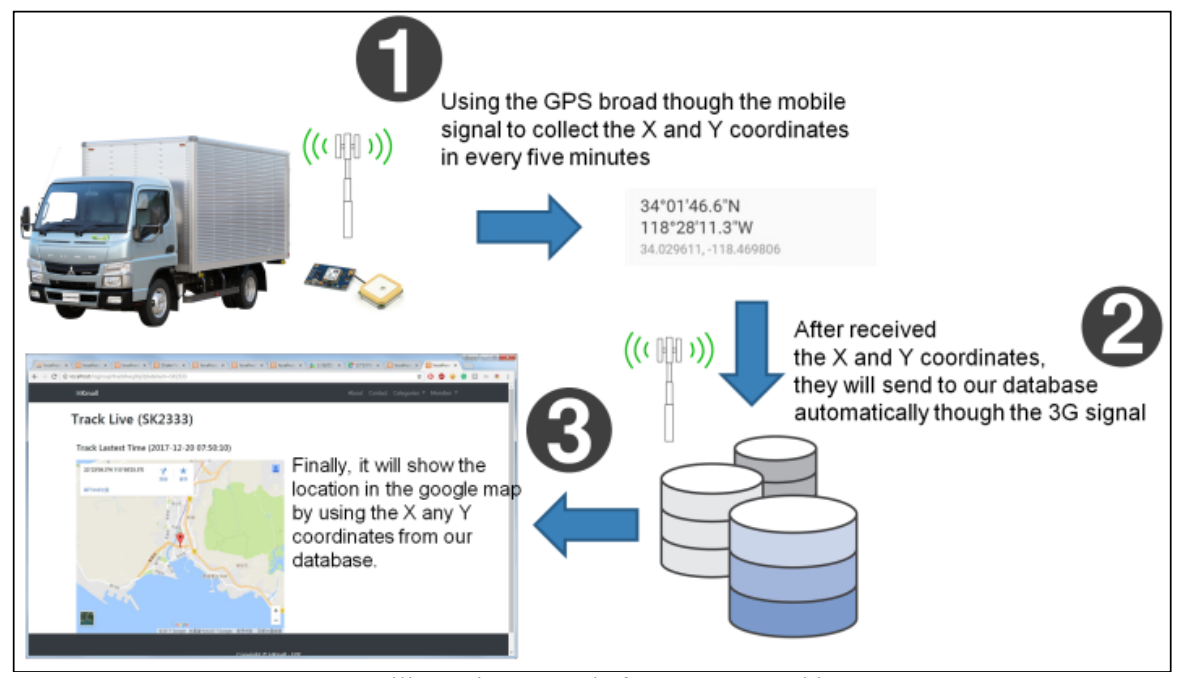

Figure 3. An illustrative example for our GPS tracking system 


\subsection{System requirements}

For software requirement, we use the following software during our system development:

PHP - it is used for webpage design

- $\quad$ PHPMyAdmin - it is used for database administration

- $\quad$ NetBeans - it is used for web development tool

- $\quad$ Arduino IDE - it is used to develop our tracking system (as shown in Figure 4)

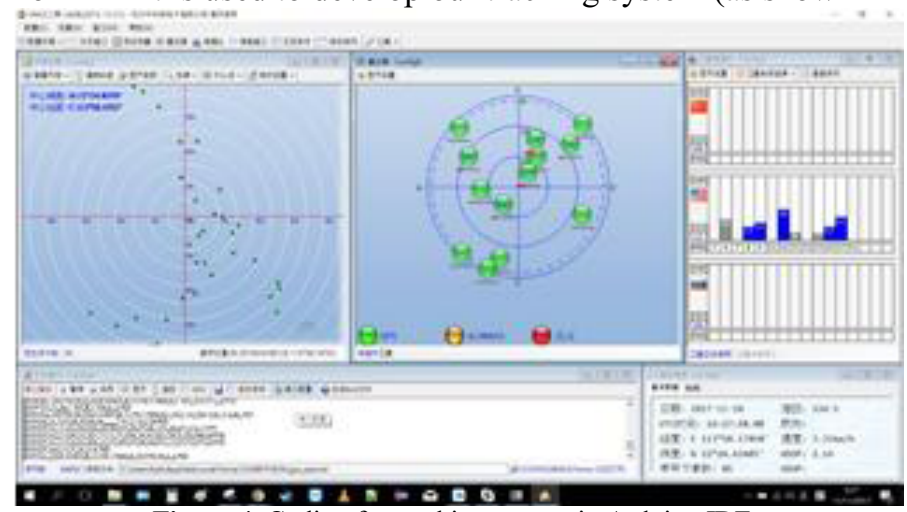

Figure 4. Coding for tracking system in Arduino IDE

For hardware requirement, we used low-cost hardware for our system development for cost effectiveness. They are:

QUECTEL MC20 sensor (Figure 5) - It is a high-performance GPS positioning module and it's in tiny size. It works with AT command and includes Bluetooth 3.0 to support SIM and USIM card.

ARDUINO UNO R3 motherboard (Figure 6) - A microcontroller board based on the ATmega328P. It has 14 digital input/output pins, 6 analog inputs, a $16 \mathrm{MHz}$ quartz crystal, a USB connection, a power jack, an ICSP header and a reset button.

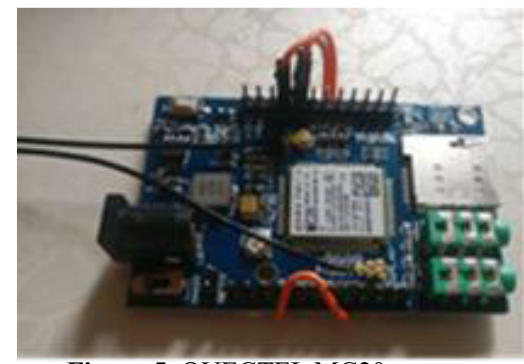

Figure 5. QUECTEL MC20 sensor

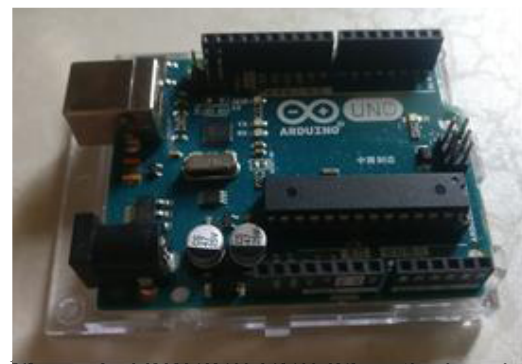

Figure 6. ARIDUINO UNOTR3 motherboard

\section{Result}

In the online shopping system, after customers selecting target product (Figure 7) and choose the payment method (Figure 8), they can check the purchase record. After the order was shipped, the GPS function will start at the same time and customers can click the "More Details" (Figure 9). The consumer can track the location of their product by 
clicking on the "Click me to check real-time tracking" (Figure 10). The location will be updated automatically every 5 minutes (Figure 11).

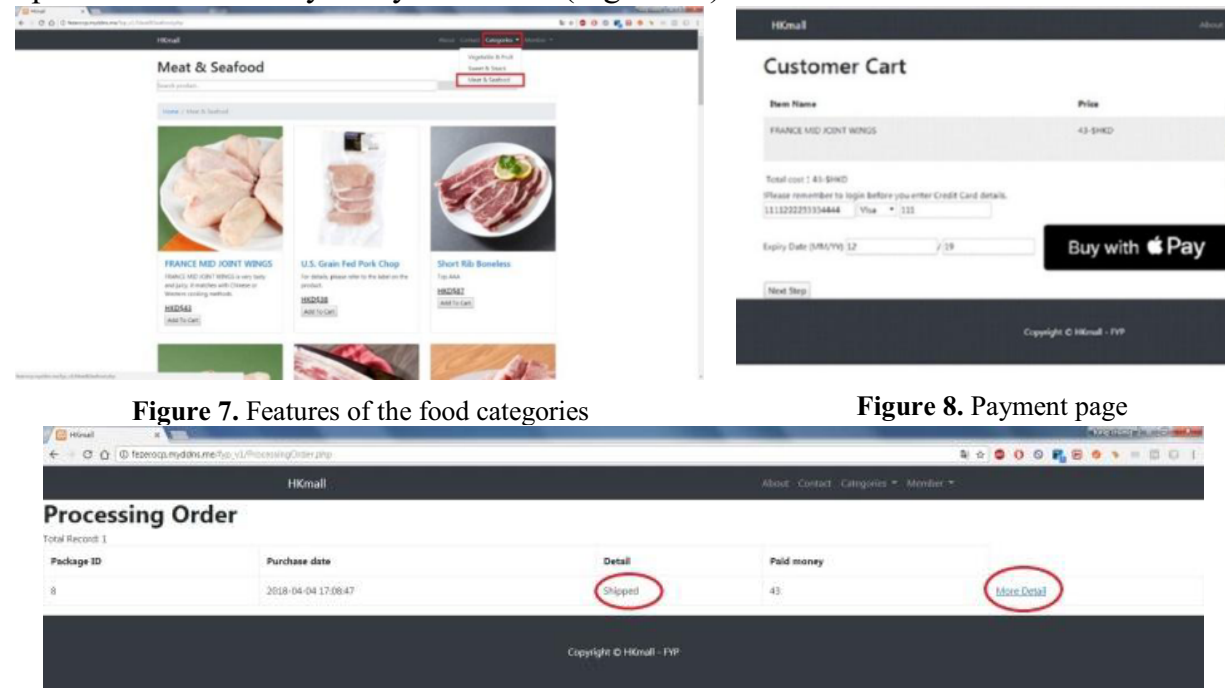

Figure 9. Checking on shipment

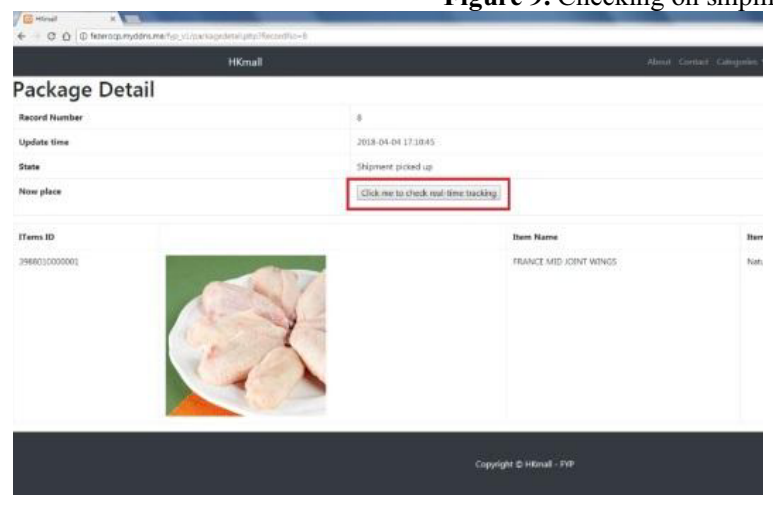

Figure 10. Tracking system

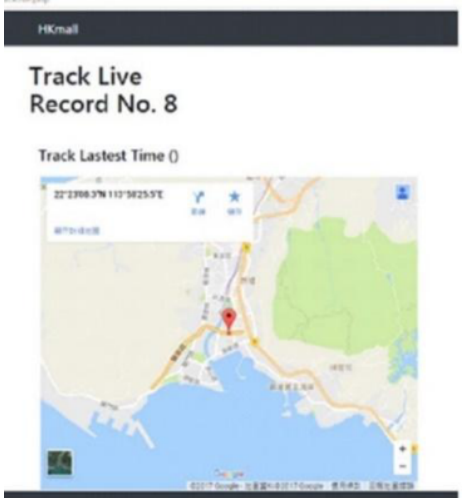

Figure 11. Real-time GPS tracking system

\section{Conclusion and Future Work}

In this paper, we have proposed a low-cost fresh food delivery tracking system by using GPS technology. The tracking device can rely information concerning the current location of the vehicle and update the information in the database of the online shopping system. Consumers can track the delivery and arrival of their grocery products to ensure the freshness of products. Additionally, the GPS system allows the consumers to manage their schedule more efficiently as they do not need to stay at home to wait for the package arrival after ordering their goods. As the cost of this fresh food delivery tracking system is low, it is suitable for online shop of start-ups. As huge amount of data on food purchase and delivery is collected, we can use these data to analyze and obtain an optimized schedule and route for food delivery. In the future 
work, we will investigate route selection for food delivery, especially for the case that we have a lot of bookings but not enough means for delivery.

\section{References}

[1] Grewal D, Roggeveen AL \& Nordfält, J (2017), The Future of Retailing. Journal of Retailing 93, 1-6.

[2] Inman JJ \& Nikolova H (2017), Shopper-Facing Retail Technology: A Retailer Adoption Decision Framework Incorporating Shopper Attitudes and Privacy Concerns. Journal of Retailing 93, 7-28.

[3] Verhoef PC, Lemon KN, Parasuraman A, Roggeveen A, Tsiros M \& Schlesinger LA (2009), Customer Experience Creation: Determinants, Dynamics and Management Strategies. Journal of Retailing 85, 3141.

[4] Deloitte (2016), Retail Trends in 2016, (accessed October 11, 2018), https://www2.deloitte.com/qa/en/pages/consumer-business/articles/retail-trends-2016.html

[5] Salman A, Abdullah MYH, Aziz J, Ahmad AL \& Kee CP (2013), Utilising information and communication technologies (ICT) for development: What research contributes. Journal of Asian Pacific Communication 23, 239-251.

[6] Yu T \& Wu G (2007), Determinants of internet shopping behaviour: an application of reasoned behaviour theory. International Journal of Management 24, 744-762.

[7] Childers TL, Carr CL, Peck J \& Carson S (2001), Hedonic and utilitarian motivations for online retail shopping behavior. Journal of Retailing 77, 511-535.

[8] Abd. Mukti N (2017), Barriers to putting businesses on the internet in Malaysia. The Electronic Journal of Information Systems in Developing Countries 2, 1-6.

[9] Katawetawaraks C \& Wang CL (2011), Online Shopper Behavior: Influences of Online Shopping Decision. Asian Journal of Business Research 1, 66-74.

[10] Shah Alam S \& Mohd. Yasin N (2010), The antecedents of online brand trust: Malaysian evidence, Journal of Business Economics and Management 11, 210-226.

[11] Omar NA, Shah Alam S, Abdul Aziz N \& Nazri MA (2011), Retail Loyalty Programs in Malaysia: The Relationship of Equity, Value, Satisfaction, Trust, and Loyalty among Cardholders, Journal of Business Economics and Management 12, 332-352.

[12] Shah MH, Peikari HR \& Mohd. Yasin N (2014), The determinants of individuals' perceived e-security: Evidence from Malaysia. International Journal of Information Management 34, 48-57.

[13] Dukare, S. S., Patil, D. A., \& Rane, K. P. (2015). Vehicle tracking, monitoring and alerting system: a review. International Journal of Computer Applications, 119(10).

[14] Maurya, K., Singh, M., \& Jain, N. (2012). Real time vehicle tracking system using GSM and GPS technology-an anti-theft tracking system. International Journal of Electronics and Computer Science Engineering. ISSN, 22771956, V1N3-1103.

[15] Liu, Z., Zhang, A., \& Li, S. (2013, July). Vehicle anti-theft tracking system based on Internet of things. In Proceedings of 2013 IEEE International Conference on Vehicular Electronics and Safety (pp. 48-52). IEEE.

[16] Li, X., Yao, X., Murphey, Y. L., Karlsen, R., \& Gerhart, G. (2004, August). A real-time vehicle detection and tracking system in outdoor traffic scenes. In Proceedings of the 17th International Conference on Pattern Recognition, 2004. ICPR 2004. (Vol. 2, pp. 761-764). IEEE.

[17] Eken, S., \& Sayar, A. (2014, June). A smart bus tracking system based on location-aware services and QR codes. In 2014 IEEE International Symposium on Innovations in Intelligent Systems and Applications (INISTA) Proceedings (pp. 299-303). IEEE.

[18] Salim, K. A., \& Idrees, I. M. (2013). Design and implementation of web-based GPS-GPRS vehicle tracking system. International Journal of Science, Engineering and Computer Technology, 3(12), 443.

[19] Hsu, C.I., Hung, S.F. and Li, H.C., 2007. Vehicle routing problem with time-windows for perishable food delivery. Journal of food engineering, 80(2), pp.465-475.

[20] Nakandala, D., Lau, H. and Zhang, J., 2016. Cost-optimization modelling for fresh food quality and transportation. Industrial Management \& Data Systems.

[21] Wang, Y.M. and Yin, H.L., 2018. Cost-optimization problem with a soft time window based on an improved fuzzy genetic algorithm for fresh food distribution. Mathematical Problems in Engineering, 2018.

[22] Chen, J., Gui, P., Ding, T., Na, S. and Zhou, Y., 2019. Optimization of Transportation Routing Problem for Fresh Food by Improved Ant Colony Algorithm Based on Tabu Search. Sustainability, 11(23), p.6584. 